\title{
Admission of suspicion as a function of information source: Tip-off vs. situational cues
}

\author{
BENJAMIN H. NEWBERRY \\ Kent State University, Kent, Ohio 44240
}

\begin{abstract}
Two studies were run in which subjects received information about a fake opponent in a two-person game either from a confederate tip off or from situational cues designed to allow the subject to penetrate the deception unaided. In both experiments, subjects given the tip off reported less suspicion of the opponent than did those using situational cues. Probes were run to check tip-off information transmission in both experiments. In Experiment II a preinstruction manipulation was used to check for awareness of the actual purpose of the experiment and suspicion of the confederate tip off, but no evidence for these unwanted artifacts was found. The results suggest that subjects may be candid about their interpretations, at least if their suspicions do not derive from peers.
\end{abstract}

Independent and controlled variables are often viewed as affecting internal processes which in turn mediate behavior. With this implicit assumption, the interpretation of data will depend upon the constructions of the situation made by the subjects. It then becomes important to assess the degree to which subjects fail to interpret the experiment in the expected manner. While most concern about subjects' interpretations of experiments has been voiced with regard to studies using deception (McGuire, 1969; Kelman, 1967; Orne \& Holland, 1968; Schultz, 1969), there is no reason to believe that the problem is limited to those areas.

One technique that nas been used to manipulate subjects' expectations and interpretations is the confederate tip off, in which they are given information by an individual who has presumably already participated in the experiment. Several studies using this method have been reported; in each case the confederate provided information of a sort that experimenters do not usually wish their subjects to have. In a study by Levy (1967), the confederate explained the contingencies of a verbal conditioning paradigm. Golding and Lichtenstein (1970) had the confederate inform subjects about false heart rate feedback. In a study by Newberry (1973), the confederate supplied answers to problems the subjects were to solve in the experiment. In all of these studies, the subjects were asked at the end of the experiment whether they had been told anything. The questioning techniques varied from requesting a saimple yes-no to extended interviews, but in every case a large proportion of the subjects denied receiving any information. Levy (1967) also found that the tipped-off subjects were more reluctant to admit suspicion of the experiment than were naive subjects. In the Levy and the Newberry (1973) studies, the tip off significantly affected performance.

\footnotetext{
*The author wishes to thank Joseph Gildow, Diane Semone, Richard Laurie, and Douglas Schultheis for their aid in collecting the data.
}

These experiments present a discouraging picture of researchers' ability to detect subjects whose beliefs or suspicions might cloud the interpretation of results. The possibility exists, however, that low admission rates found in studies using the confederate tip off are peculiar to the method rather than indicative of general deviousness among subjects. Subjects who receive information from another may be more reluctant to admit their sophistication than are those who develop the same suspicions on their own. The present experiments attempt to test this possibility by comparing willingness to admit suspicion of a deception when it derives from a tip off with willingness to admit the same suspicion when it derives from the subject's own experience in the situation.

The cover experiment was a competitive nonzero sum game with a monetary prize to the winner. The deception was that the game opponent was not a genuine subject. This deception is relatively common and relatively innocuous, and it allows the manipulation of subjects' ability to see through the deception unaided. Experiment I compared admission following a tip off with that occurring when situational cues were available. Experiment II replicated the major conditions of the first with additional controls for possible artifactual explanations of the results.

\section{EXPERIMENT I}

\section{Method}

Subjects and Design. Subjects were 60 male introductory psychology students. A certain amount of experimental participation or extra reading was a course requirement. Beyond the requirement, experimental participation or reading were given course credit. Tip off (presence or absence of information from a confederate) and realism (variation in the experimental situation designed to vary the proba bility that subjects would see through the deception by themsleves) were varied factorially with 10 subjects per cell. In addition, to check tip-off information transmission, 20 subjects, 10 given the tip off and 10 not, were run as probes.

Game and Information Manipulations. In the tip-off condition a male confederate seated in the waiting room delivered the 
following communication after ascertaining that the subject was waiting for the correct experiment:

"I took that one. I think it was last week (or the beginning of the week). That experiment is really screwed up. You have to play this game for points-the one with the most points wins. But your opponent is a fake because the experimenter is really controlling the whole thing."

The exact wording was chosen by the confederate to fit his own conversational style. If the subject was not to be tipped off, the confederate did not initiate conversation. The tip-off confederate and the experimenter were unaware of which condition was administered by the other to any particular subject.

In the realistic condition the subject and confederate were joined by a second male confederate (the game opponent) following the tip off or a suitable amount of time. Shortly thereafter, the opponent and the subject were called by a female experimenter. They were seated at a table on opposite sides of a 12-in.-high barrier, and the game was explained to both. It was explained that the player who won would receive money (up to $\$ 3.00$ ) in proportion to the amount of his win, that responses for each trial were to be written on cards and handed to the experimenter, and that each would receive a token after each trial indicating the number of points won or lost on that trial. The game was played for 20 trials with the opponent's responses constituting a random sequence. Both players then filled out a postexperimental questionnaire. The opponent acted and was treated as a genuine subject throughout. When both had completed the questionnaire, the experimenter paid if the subject won and apprised him that his opponent was a confederate.

In the unrealistic condition there was no second player, and the barrier was raised to $3 \mathrm{ft}$ in height by resting a second piece of plywood atop the first. The subject could ascertain that he had no opponent by looking through the thin crack between the segments. He was told that his opponent, another male introductory student, was already seated behind the barrier, and the game instructions were then addressed to him alone. The opponent's responses were all of one type for the first 16 trials. No tokens were dropped on the opponent's side of the table. After the last trial, the subject filled out the questionnaire, was paid if he won, and was debriefed about the opponent.

Postexperimental Questionnaire. The questionnaire for other than the probe conditions consisted of 13 items, all but 2 of which were fillers. Some items were free response; others consisted of a yes-no response and a strength of belief scale to be checked if yes was checked. The 12th item, on suspicion of the opponent, was of the latter type. It read, "Did you think at any time that the experimenter was controlling the choices made by the other player or that the other player was not a genuine subject?" Including the 4-point strength of belief portion, the item provided a 5-point scale. The 13 th item, alone on the last page and in a yes-no format read, "Had you heard anything about this experiment before you participated in it?"

Probe Condition. Probe subjects were told that the experiment concerned people's ability to remember the content of conversations, and that, to study this problem, half the subjects in the experiment were told something about the experiment in the waiting room. They were then given a questionnaire asking if they had been told anything and presenting eight true-false items on the tip-off content. They were instructed to give their best guesses if they had been told nothing. The question on the opponent read, "There is another subject who is a fake subject.'

\section{Results}

Table 1 presents mean suspicion scores for Experiment I and Experiment II, as well as the number
Table 1

Self-Rated Suspicion of Game Opponent: Experiments I and II

\begin{tabular}{|c|c|c|c|c|}
\hline & \multicolumn{4}{|c|}{ Experiment I } \\
\hline & & Reali & stic & Unrealistic \\
\hline \multirow{4}{*}{$\begin{array}{l}\text { Tip Off } \\
\text { No Tip Off }\end{array}$} & & 1.40 & (2) & $3.70(8)$ \\
\hline & & 1.00 & (0) & $4.60 \quad(10)$ \\
\hline & \multicolumn{4}{|c|}{ Experiment II } \\
\hline & \multicolumn{2}{|c|}{$\begin{array}{c}\text { No Infor- } \\
\text { mation }\end{array}$} & Tip Off & Unrealistic \\
\hline Preinstruction & 1.57 & $(2)$ & 1.14 & 3.43 \\
\hline No Preinstruction & 1.57 & (1) & $1.57 \quad$ (3) & 4.14 \\
\hline
\end{tabular}

Note-Numbers in parentheses refer to the number of subjects in a condition who indicated any suspicion at all.

of subjects who indicated any suspicion at all by checking "yes" on the first part of the suspicion item. Analysis of variance of scaled suspicion in Experiment I produced a significant realism effect $(F=80.54$, df $=$ $1 / 36, p<.0001)$. Neither the tip-off effect $(p>.25)$ nor the interaction $(F=3.91$, df $=1 / 36, p=.053)$ was significant, although the interaction nearly reached the .05 level. Subjects in the non-tip-off/realistic condition all reported the lowest possible suspicion level (scored as 1). Therefore, Sutcliffe's (1957) chi-square method was applied to the numbers of subjects indicating suspicion. The results paralleled the analysis of variance, with a significant realism effect $\left(\chi^{2}=25.60, \mathrm{df}=1, \mathrm{p}<.001\right)$, no tip-off effect $\left(\chi^{2}=0.00\right)$, and no interaction $(p>.20)$.

The probe data indicated good information transmission in the tip off. The mean number of items correct for the tipped-off probes was 6.2 ; that for the naive probes was $4.5(\mathrm{t}=4.02, \mathrm{df}=18, \mathrm{p}<.001)$. All tipped-off probes answered the item on the opponent correctly, whereas only 2 of 10 naive probes did so. The difference reaches .01 by the Fisher exact test (Siegel, 1956).

Of the tip-off subjects, 3 of 10 in the realistic condition, 4 of 10 in the unrealistic condition, and 10 of 10 in the probe condition admitted being given information. One of $\mathbf{3 0}$ subjects not given the tip off indicated receiving information. Given the competitive matrix and the use of monetary incentives, game performance differences due to treatments were not expected, and none occurred.

\section{EXPERIMENT II}

The results of Experiment I, suggesting that subjects who see through a deception on their own are likely to admit suspicion, imply a qualification of earlier conclusions and support those (e.g., Milgram, 1972) who rely on subjects' postexperimental statements. Experiment II attempted to replicate these findings and also included a type of "quasi-control" manipulation as a check on one possible explanation of the results. The 
transparency of the unrealistic condition could induce subjects to suspect that they are being allowed to penetrate the deception. Their high suspicion scores could then be a result of a desire to produce "good" data (Orne, 1962, 1969). The check consisted of preinstructing subjects that the experiment was deceptive and asking them to penetrate the deception. Holland (1967) used this technique to test the ecological validity of Milgram's (1963) obedience paradigm. This method was used in a way nearly identical to that of the present study by Nelson (1973), who found that preinstructions produced increased suspicion of a tip-off confederate, a taped conversation, and a conformity situation.

\section{Method}

Subjects and Design. Subjects were 62 males enrolled in introductory psychology. Subject pool requirements were the same as in Experiment 1 . A 3 by 2 factorial design employed three information conditions-tip off, unrealistic, and no information-crossed with the preinstruction manipulation. Seven subjects were run in each cell. Twenty probes were run as in Experiment $\mathrm{I}$.

Preinstruction. Preinstruction subjects reported to a faculty office, where they were met by a graduate student who informed them that they were going to hear instructions written for them by the faculty member in charge of the experiment. They were told that they had a special role to play in evaluating deception in psychological experiments and that some psychologists, including the author, "believe that students of average intelligence are not easily fooled by attempts to disguise experiment." It was explained that they were going to be in an experiment whose actual purpose would be disguised. They were instructed to penetrate the deception but to act as naive subjects except for a questionnaire item asking for their hypotheses as to the actual purpose of the experiment. They were also told that the experimenter in the laboratory was unaware of the preinstruction. Preinstruction subjects were then sent to the laboratory waiting area and run under one of the information conditions. The experimenter and confederates operating in the laboratory and waiting room were not aware that preinstruction was being given.

Game, Questionnaire, and Interview. The game and postexperimental questionnaire differed from Experiment $I$ in that the opponent's responses in the unrealistic condition followed the same random schedule as in the other conditions, and the postexperimental questionnaire included, immediately before the foreknowledge item, an item asking the subject to, "write down any ideas that have occurred to you concerning the purpose of this experiment no matter how farfetched they seem." After taking the questionnaire, all subjects except probes returned to the faculty office for an interview conducted by the same person who administered the preinstruction. Five free-response questions converged on the issue of subject honesty. A sixth item explained that the experiment was designed to study admission of suspicion and asked if the subject had ever thought that to be its purpose. Responses were recorded in longhand.

\section{Results}

Subject-Rated Suspicion of Opponent. Table 1 gives means of subjects' rated suspicion of the opponent. A significant information effect occurred $(F=16.70, \mathrm{df}=$ $2 / 36, p<.001$ ), but neither the preinstruction effect nor the interaction was significant ( $p>.20$ for both) Newman-Keuls tests on the information effect indicated greater suspicion in the unrealistic condition than in the tip-off or no-information conditions, which latter two did not differ significantly.

Open-Ended Question and Interview. Interview protocols and questionnaire responses on the purpose of the experiment were rated on suspicion that the purpose of the experiment was to study admission of suspicion. suspicion of the tip off, and suspicion of the opponent. The interviews and written responses were rated separately by three graduate students who were unfamiliar with the study and blind as to treatment conditons. Each written response and open-ended interview response was rated on a 5-point scale. Ratings were summed across raters and across questions of the interview to give minimum scores of 3 for the questionnaire and 15 for the interview.

Table 2 gives mean ratings for each suspicion category for the questionnaire and the interview. As the means indicate, the three judges were in near perfect agreement as to the lack of suspicion of the experiment's true purpose and of the tip off. The final interview question, explaining the purpose of the study and asking the subject whether he had recognized it, elicited only one affirmative response from 42 subjects. Interview data on

Table 2

Judges' Ratings of Free Response Questionnaire Item and Postexperimental Interview

\begin{tabular}{|c|c|c|c|c|c|c|}
\hline \multirow[b]{2}{*}{ Condition } & \multicolumn{2}{|c|}{$\begin{array}{c}\text { Suspicion of True } \\
\text { Purpose of Experiment }\end{array}$} & \multicolumn{2}{|c|}{$\begin{array}{c}\text { Suspicion of } \\
\text { Game Opponent }\end{array}$} & \multicolumn{2}{|c|}{$\begin{array}{c}\text { Suspicion of Waiting } \\
\text { Room Tip Off }\end{array}$} \\
\hline & $\mathrm{Q}^{*}$ & I & Q & I & Q & I \\
\hline \multicolumn{7}{|l|}{ Preinstruction } \\
\hline No Information & 3.00 & 15.00 & 3.00 & 15.29 & 3.00 & 15.00 \\
\hline Tip Off & 3.00 & 15.86 & 4.71 & 16.29 & 3.00 & 15.00 \\
\hline Unrealistic & 3.14 & 15.00 & 6.14 & 21.14 & 3.00 & 15.00 \\
\hline \multicolumn{7}{|l|}{ No Preinstruction } \\
\hline No Information & 3.00 & 15.00 & 3.00 & 15.00 & 3.00 & 15.00 \\
\hline Tip Off & 3.00 & 15.00 & 3.00 & 17.00 & 3.00 & 15.00 \\
\hline Unrealistic & 3.00 & 15.00 & 3.00 & 24.71 & 3.00 & 15.00 \\
\hline
\end{tabular}

*Means in $Q$ column are from free response questionnaire item.

tMeans in I column are from postexperimental interview. 
suspicion of the opponent, which provided the greatest variability in ratings, were used to assess interjudge reliability. Spearman rank coefficients were $.721, .729$, and .829 (all $\mathrm{p}<.01$ ) for the three judge pairings. Ratings of suspicion of the opponent in the preinstruction/tip-off and preinstruction/unrealistic conditions were used to compare the interview and questionnaire. The Spearman rank coefficient was .848 $(\mathrm{p}<.01)$.

The nature of the data made effects of analysis of treatment effects reasonable only for suspicion of the opponent in the interview. Only the information effect was significant $(F=13.46 . \mathrm{df}=3 / 36, p<.001)$, with greater suspicion in the unrealistic condition than in the other information conditions ( $p>.20$ for preinstruction and interaction effects).

The failure of the preinstruction manipulation to affect any category of suspicion, while indicating a lack of unwanted artifacts, leaves the possibility that the preinstruction was not understood or not taken seriously. As a rough check on this possibility, an analysis was done on the number of words written on the questionnaire item asking for hypotheses. Mean word counts are given in Table 3. The preinstruction effect $(F=17.61, \mathrm{df}=1 / 36, \mathrm{p}<.001)$ and the information effect $(F=5.57, \mathrm{df}=2 / 36, \mathrm{p}<.01)$ were significant. Output was significantly higher in the unrealistic condition than in the other information conditions. The interaction was not significant $(p>.20)$.

Probe Condition and Admission of Tip Off. Tipped-off probes performed better than naive probes on the question regarding the opponent $(10 / 10$ vs $3 / 10$, $\mathrm{p}=.02)$ and on the content questions as a whole $(\mathbf{M}=$ 7.2 and 3.5, $\mathrm{t}=12.33$, df $=18, \mathrm{p}<.001$ ). As in Experiment $I$, these data indicate adequate information transmission in the tip off.

Results on admission of the waiting-room tip off generally paralleled those of Experiment I. Ten tipped-off probes, no naive probes, two of seven subjects in the no preinstruction/tip-off condition, three of seven in the preinstruction/tip-off condition, and 5 of 28 in the other conditions admitted having heard something about the experiment before participating.

\section{DISCUSSION}

In both experiments, subjects enabled to see through the deception on their own indicated greater suspicion of the opponent than did those given essentially the same information by confederate tip off. There was little difference between the latter group and those given no information. These data suggest that, at least under some circumstances, subjects who penetrate deceptions on their own will be relatively candid and that a general reluctance on the part of subjects to admit their suspicions and interpretations of experiments cannot be inferred from studies using the tip-off technique. Earlier
Table 3

Number of Words Written in Response to Open-Ended Questionnaire Item

\begin{tabular}{cccc}
\hline & \multicolumn{3}{c}{ Information Condition } \\
\cline { 2 - 4 } $\begin{array}{c}\text { Preinstruction } \\
\text { Condition }\end{array}$ & $\begin{array}{c}\text { No Infor- } \\
\text { mation }\end{array}$ & $\begin{array}{c}\text { Tip } \\
\text { Off }\end{array}$ & $\begin{array}{c}\text { Unrealis- } \\
\text { tic }\end{array}$ \\
\hline Preinstruction & 44.00 & 42.42 & 74.71 \\
No Preinstruction & 24.57 & 35.86 & 13.14 \\
\hline
\end{tabular}

implications in this regard (Levy, 1967; Golding \& Lichtenstein, 1970; Newberry, 1973) must be viewed as questionable.

The data become more important for the general problem of subject candor if the difference between the unrealistic and tip-off conditions reflects a general difference in frankness due to the source of information. Data from the present experiments and earlier studies tend to support such an interpretation by calling into question two otherwise plausible artifactual explanations. The possibility that subjects in the unrealistic condition admitted suspicion because they recognized the actual purpose of the experiment is inconsistent with the failure of the preinstruction to produce indications of such a recognition. Subjects' written word counts and the successful use of technique by Nelson (1973) support the efficacy of the preinstruction manipulation itself. That the preinstruction manipulation did not affect suspicion of the opponent is somewhat surprising, but subjects may not have seen the genuineness of the opponent as relevant to the basic purpose of the experiment. Indeed, subjects' hypotheses appeared to focus on winning strategies, competitiveness, and cooperation-aspects of the game itself.

Data from the probe conditions and from earlier studies showing performance differences as a function of a tip off (Levy, 1967; Newberry, 1973) are incongruent with the possibility that subjects given the tip off did not understand it and therefore were not suspicious. Further, if tipped-off subjects were merely uncertain of the truth of the confederate's information, they would be expected to respond with an indication of suspicion and low strength of belief; in fact 12 of 17 subjects given the tip off alone indicated no suspicion whatever. The fact that admission of prior information is not related to degree of use of the information in the experiment (Newberry, 1973) and that tipped-off subjects who admit foreknowledge tend to trivialize it (Glinski, Glinski, \& Slatin, 1970) suggests that such subjects are a problem whether uncertainty or a deliberate intent to deceive motivates their reticence.

There are no data strongly disconfirmatory of the possibility that subjects recognized the tip-off confederate as a plant and withheld information in response to the attempted deception. Since, however, the manipulation is unusual and occurs outside the 
laboratory, and since subjects do talk about experiments (Taub \& Fanow, 1973; Wuebben, 1967), it seems unlikely that the tip off was penetrated. The lack of suspicion in the questionnaire and interview is consistent with the integrity of the tip off, although, as with the opponent, the tip off could have been seen as irrelevant to the experiment's aim.

If subjects with peer-derived information are deliberately dissimulating, the reasons for their behavior become an issue of some importance. Unfortunately, no more than speculation is possible on this question. Reactance (Brehm, 1966) may be aroused due to the inability to maintain a naive role, or implicit norms may be violated by admitting prior information and by exten. sion suspicions derived from such information. The $100 \%$ admission rate among tipped off probes, for whom the legitimacy of the information was obvious, and the fact that subjects do discuss experiments are at least consistent with the latter hypothesis.

Of course, the various potential explanations of the difference in candor between tipped-off subjects and those using situational cues are not mutually exclusive. The results of the present experiments do, however, indicate some boundaries to the problem of detecting sophisticated subjects.

\section{REFERENCES}

Brehm, J. W. A theory of psychological reactance. New York: Academic Press, 1966.

Glinski, R. J., Glinski, G. C., \& Slatin, G. T. Nonaivete contamination in conformity experiment: Sources, effects, and complications for control. Journal of Personality and Social Psychology, 1970, 16, 478-485.

Golding, S. L., \& Lichtenstein, E. Confession of awareness and prior knowledge of deception as a function of interview set and approval motivation. Journal of Personality and Social Psychology, 1970, 14, 213-223.
Holland, C. H. Sources of variance in the experimental investigation of behavioral obediance. Unpublished doctoral dissertation, University of Connecticut, 1967. (Cited in M. T. Orne, \& C. H. Holland. On the ecological validity of laboratory deceptions. International Journal of Psychiatry, $1968,6,282-293$ ).

Kelman, H. C. Human use of human subjects: The problem of deception in social psychological experiments. Psychological Bulletin, 1967, 67, 1-11.

Levy, L. A wareness, learning and the beneficient subject as expert witness. Journal of Personality and Social Psychology. $1967,6,363-370$.

McGuire, W. J. Suspiciousness of experimenter's intent. In R. Rosenthal and R. L. Rosnow (Eds.), Artifact in behavioral research. New York: Academic Press, 1969.

Milgram, S. Interpreting obediance: Error and evidence. In A. G. Miller (Ed.), The social psychology of psychological research. New York: The Free Press, 1972.

Milgram, S. Behavioral study of obediance. Journal of Abnormal and Social Psychology, 1963, 67, 371-378.

Nelson, C. Admission of prior information as a function of information source and task type. Unpublished Master's thesis, Kent State University, 1973.

Newberry. B. H. Truthtelling in subjects with information about experiments: Who is being deceived? Journal of Personality and Social Psychology, 1973, 25, 369-374.

Orne, M. T. On the social psychology of the psychological experiment: With particular reference to demand characteristics and their implications. American Psychologist $1962,17,776-783$.

Orne, M. T. Demand characteristics and the concept of quasicontrols. In R. Rosenthal and R. L. Rosnow (Eds.) Artifact in behavioral research. New York: Academic Yress. 1969.

Orne, M. T., \& Holland, C. H. On the ecological validity of laboratory deceptions. International Journal of Psychiatry, $1968,6,282-293$.

Schultz, D. P. The human subject in psychological research. Psychological Bulletin, 1969, 72, 214-228

Siegel, S. Nonparametric statistics. New York: McGraw-Hill, 1956.

Sutcliffe, J. P. A general method of analysis of trequency data for multiple classification designs. Psychological Bulletin, $1957,54,134-137$.

Taub, S. I., \& Farrow, B. J. Reinforcement effects on intersubject communication: The scuttlebut effect. Perceptual and Motor Skills, 1973, 37, 15-22.

Wuebben, P. L. Honesty of subjects and birth order. Journal of Personality and Social Psychology, 1967, 5, 350-352.

(Received for publication February 7,1974 ; revision accepted August 13, 1974.) 